\title{
PELAKSANAAN LAYANAN E-PUSKESMAS DI PUSKESMAS AMBACANG KECAMATAN KURANJI KOTA PADANG
}

\author{
Arya Bagus Saputro \\ Jurusan Ilmu Administrasi Publik, FIS Universitas Negeri Padang, aryabagussaputro@gmail.com
}

\section{Fachri Adnan dan Zikri Alhadi}

Jurusan Ilmu Administrasi Publik, FIS Universitas Negeri Padang, fachriadnan@yahoo.com, ianunpzikri@yahoo.co.id

\begin{abstract}
Abstrak
Penelitian ini bertujuan untuk mengetahui pelaksanaan layanan e-Puskesmas di Puskesmas Ambacang Kecamatan Kuranji Kota Padang, untuk mengetahui faktor-faktor pendukung dan penghambat dalam pelaksanaan layanan e-Puskesmas di Puskesmas Ambacang. Penelitian ini merupakan penelitian kualitatif dengan metode deskriptif. Penelitian ini dilakukan di Puskesmas Ambacang Kecamatan Kuranji Kota Padang. Informan penelitian ditentukan secara Purposive sampling. Data yang dikumpulkan yakni berupa data sekunder dan data primer melalui wawancara, observasi dan studi dokumentasi. Uji keabsahan data dilakukan dengan trianggulasi kemudian data dianalisis dengan mereduksi data, display data dan menarik kesimpulan selama penelitian dilakukan. Hasil penelitian ini menunjukkan bahwa pelaksanaan layanan ePuskesmas belum terlaksana dengan baik sehingga pelaksanaan layanan tersebut menjadi belum efektif. Faktor pendukung yang ditemukan adalah anggaran yang mencukupi dalam menerapkan e-Puskesmas, adanya perubahan paradigma pegawai di Puskesmas Ambacang serta adanya dukungan dari pimpinan. Faktor penghambat yaitu kurangnya ketersediaan infrastruktur yang memadai, tingkat konektivitas internet tidak sesuai dengan kebutuhan, kurang memadainya sumber daya manusia dalam hal teknologi informasi, kurangnya sosialisasi mengenai layanan e-Puskesmas serta kurangnya pengetahuan masyarakat mengenai layanan e-Puskesmas di Puskesmas Ambacangtersebut.
\end{abstract}

Kata Kunci: Pelayanan Publik, e-Government, e-Puskesmas

\begin{abstract}
The purpose of this research is to know the implementation of e-Puskesmas service at Ambacang Community Health Center of Kuranji Subdistrict, Padang City, to know the supporting and inhibiting factors in the implementation of e-Puskesmas service at Ambacang Community Health Center. This research is a qualitative research with descriptive method. This research was conducted at Puskesmas Ambacang Kecamatan Kuranji Kota Padang. The research by purposive sampling. The data collected are secondary data and primary data through interview, observation and documentation study. Test data validity is done with trianggulasi then data analyzed by reducing data, display data the results of this study indicate that the implementation of e-Puskesmas service has not been implemented properly so that the implementation of the service becomes not effective. Supporting factors were found to be sufficient budget in applying e-Puskesmas, a change of paradigm of staff at Ambacang Community Health Center. Inhibiting factors are lack of adequate infrastructure availability, internet connectivity level is not appropriate, lack of socialization about e-Puskesmas service.
\end{abstract}

Keywords: Public Service, e-Government, e-Puskesmas

\section{PENDAHULUAN}

Permasalahan mengenai pelaksanaan layanan ePuskesmas di Puskesmas Ambacang Kota Padang ini terlihat dari Kurang memadainya sumber daya manusia dalam bidang informasi teknologi, kurangnya pengetahuan masyarakat tentang layanan e-Puskesmas, padahal memudahkan masyarakat dalam hal pelayanan dan kurangnya memadainya infrastruktur dalam menerapkan e-Puskesmas. Dari observasi yang penulis lakukan di Puskesmas Ambacang pelayanan kesehatan di Puskesmas masih menggunakan pelayanan konvensional dan melakukan pencatatan data pasien menjadi dua kali. Masyarakat yang berobat di Puskesmas masih kurang memanfaatkan pelayanan e-Puskesmas yang diterapkan di Puskesmas Ambacang. 
Aplikasi untuk pelayanan kesehatan telah dikembangkan dalam memberikan pelayanan kesehatan untuk semua masyarakat yang ada ditiap-tiap puskesmas yang ada di Kota Padang yang bernama aplikasi ePuskesmas. Aplikasi e-Puskesmas adalah wujud dari penerapan teknologi informasi dan komunikasi yang akan memberikan kontribusi yang sangat besar dalam memberikan pelayanan yang optimal kepada masyarakat. Aplikasi e-Puskesmas merupakan salah satu modul aplikasi untuk perancangan kota pintar yang dikembangkan pemerintah Dinas Kesehatan bekerjasama dengan PT. Infokes Indonesia. Info kesehatan (Infokes) Mobile Apps terintegrasi dengan e-puskesmas dan telah digunakan di 22 puskesmas di Kota Padang. Diharapkan keberadaan Infokes Mobile Apps ini dapat membantu dan meningkatkan pelayanan kesehatan di Sumbar.

Menurut Indrajit (2002) E-Government adalah sebuah gagasan interaksi yang baru dari pemerintah kepada masyarakat dan kalangan lainnya (stakeholder); dimana dalam kenyataannya melibatkan pemanfaatan teknologi informasi (terutama internet) maupun media elektronik; dengan tujuan memperbaiki dan meningkatkan mutu kualitas untuk pelayanan yang dilakukan salah satunya di bidang kesehatan.

Rumusan masalah dalam penelitian ini adalah bagaimana pelaksanaan layanan e-Puskesmas Ambacang Kecamatan Kurani Kota Padang, faktor-faktor yang menjadi pendukung dan penghambat dalam pelaksanaan layanan e-Puskesmas di Puskesmas Ambacang Kecamatan Kuranji Kota Padang.

Pengukuran performa pemerintahan yang menerapkan e-government salah satunya dalam bidang kesehatan terdapat lima dimensi. Kelima dimensi itu adalah: manfaat, efisiensi, partisipasi, transparansi, dan manajemen perubahan yang dikemukakan Stiftung (2001) dalam Indrajit (2005:46) Menjelaskan kelima dimensi untuk melihat pelakasanaan e-Government yaitu:

1. Dimensi pertama, manfaat. Dimensi manfaat berhubungan dengan kualitas dan kuantitas layanan yang diberikan dan bagaimana masyarakat mendapatkan manfaat dari layanan tersebut.

2. Dimensi kedua, efisiensi. Efisiensi berhubungan dengan bagaimana teknologi bisa mempercepat proses dan meningkatkan kualitas layanan.

3. Dimensi ketiga, partisipasi. Ini berhubungan dengan pertanyaan apakah layanan yang diberikan memberikan kesempatan yang luas kepada masyarakat untuk memberikan partisipasi dalam penyampaian pendapat.

4. Dimensi keempat, transparansi. Apakah pemerintah dalam hal ini mendorong keterbukaan informasi menuju proses transparan dalam pemerintahan.
5. Dimensi kelima, manajemen perubahan. Ini terkait dengan proses implementasi apakah ada proses review yang jelas dan dikelola dengan baik.

Beberapa penelitian sebelumnya yang membahas pelayanan berbasis elektronik. Adapun penelitian terdahulu oleh Nur Mas Ammah Tahun 2016 tentang penerapan layanan electronic health (e-health) di Puskesmas Peneleh Kecamatan Genteng Kota Surabaya. Penelitian ini memperkuat penelitian sebelumnya dengan temuan pelaksanaan e-Puskesmas di Puskesmas Ambacang yang belum maksimal dalam melaksanakan pelayanan yang berbasis elektronik dan kurangnya transaparansi mengenai layanan e-Puskesmas yang akan diberikan oleh Puskesmas Ambacang kepada masyarakat di wilayah kerja Puskesmas.

Penelitian yang telah dilakukan oleh Santy Nurina Aprilia Tahun 2014 tentang Efektivitas Website Sebagai Media E-government dalam Meningkatkan Pelayanan Elektronik Pemerintah Daerah (Studi Pada Pemerintah Daerah Kabupaten Jombang). Penelitian ini memperkuat penelitian sebelumnya dengan temuan Website Pemerintah Kabupaten Jombang telah efektif sebagai media penyampaian informasi, namun sebagai media layanan elektronik (e-service) belum efektif. namun dalam penelitian ini penulis lebih memfokuskan kepada layanan e-Puskesmas sebagai media layanan elektronik untuk meningkatkan pelayanan kesehatan yang ditujukan pada masyarakat.

Berdasarkan Penelitian Rahmad Buchari pada tahun 2016. Hasil dari penelitian ini menunjukan bahwa implementasi program e-Service melalui e-Kelurahan belum berhasil. Hal ini dikarenakan adanya hambatan yang menghambat efektifitas dan efisiensi pelaksanaan program e-Kelurahan. Hambatan yang muncul dalam pelaksanaan E-Kelurahan adalah hambatan yang bersifat teknis, yakni tidak tersedianya operator yang professional dalam bidangnya agar program terlaksana secara efektif dan efisien. Penelitian ini memperkuat penelitian sebelumnya dengan temuan petugas Puskesmas belum maksimal dalam menggunakan teknologi informasi dan pengetahuan masyarakat masih kurang untuk memanfaatkan pelayanan e-Puskesmas. Namun dalam penelitian ini penulis juga menemukan pelaksanaan layanan e-Puskesmas di Puskesmas Ambacang terhambat dengan ketersediaan jaringan yang ada (tingkat koneksivitas).

Berdasarkan penelitian terdahulu yang dilalukan oleh Ayu Aditya Oktavya tahun 2015. Hasil dari penelitian ini menjelaskan bahwa penerapan electronic government (e-government) pada Kantor Pelayanan Pajak (KPP) Pratama dalam pemberian pelayanan di Kota Bontang mengenai partisipasi masyarakat masih terbilang kurang. Hal tersebut dapat dilihat dari masih apatisnya 
masyarakat dalam perkembangan teknologi khususnya penerapan electronic government (egovernment) pada Kantor Pelayanan Pajak (KPP) Pratama. Namun Kantor Pelayanan Pajak (KPP) Pratama masih kurang dalam melakukan sosialisasi maupun memberikan penjelasan secara khusus mengenai electronic government (egovernment) kepada masyarakat. Temuan penulis juga mendukung hasil penelitian sebelumnya yang mana partisipasi masyarakat masih kurang dan sosialasasi mengenai e-Puskesmas belum terlaksana dengan maksimal. Disisi lain penelitian ini meneliti tentang pelayanan berbasis elektronik di bidang kesehatan yaitu Puskesmas.

Secara umum penelitian ini sejalan dengan penelitian terdahulu yang telah dipaparkan dari beberapa jurnal diatas, hasil penelitian ini memperkuat penelitian terdahulu dengan subjek yang sama objek yang berbeda. Hasil penelitian ini menemukan bahwa terdapat beberapa kendala dalam pelaksanaan layanan e-Puskesmas di Puskesmas Ambacang diantaranya kurang memadainya sumber daya manusia dalam bidang informasi teknologi, infrastruktur yang belum memadai serta kurangnya pengetahuan masyarakat mengenai e-Puskesmas. Secara keseluruhan penelitian ini sejalan dengan temuan sebelumnya seperti masih kurangya pengetahuan masyarakat, kurangnya sosialisasi yang dilakukan serta sumber daya manusia kurang memadai dalam bidang informasi teknologi. Perbedaannya terdapat pada kegiatan pelayanan yang dilakukan Puskesmas yaitu dengan meningkatkan pelayanan kesehatan kepada masyarakat (pasien).

Terkait dengan pelaksanaan layanan e-Puskesmas yang dikembangkan Dinas Kesehatan kota Padang belum terlaksan dengan baik karena masih terdapat kekurangan pada saat pelaksanaan pelayanan kesehatan. dari beragamnya pendapat para ahli mengenai penerapan $e$ Government, peneliti mengacu kepada Dimensi $e$ Government dari Stiftung dalam Indrajit (2005:46-48) dimana pelaksanaan e-Government dilihat dari lima dimensi yaitu manfaat, efesiensi, partisipasi, transparansi dan manajemen perubahan.

\section{METODE}

Penelitian ini menggunakan pendekatan kualitatif dengan metode deskriptif. Penelitian ini dimaksudkan untuk mendeskripsikan Pelaksanaan layanan ePuskesmas di Puskesmas Ambacang Kota Padang. Penelitian ini dilakukan di Puskesmas Ambacang Kecamatan Kuranji Kota Padang, Dinas Kesehatan Kota Padang.

Dalam penelitian ini menggunakan metode purposive sampling yaitu teknik penentuan informan dengan pertimbangan tertentu yaitu terhadap orang-orang yang dapat memberikan data secara maksimal. Informan sebanyak 12 orang yang terdiri dari Kepala Puskesmas Ambacang Kota Padang, Pejabat fungsional bagian program Dinas Kesehatan Kota Padang, petugas Rekam Medis Puskesmas Ambacang, Petugas pendaftaran Puskesmas Ambacang , Tata Usaha Puskesmas Ambacang dan masyarakat (pasien) yang berobat di Puskesmas Ambacang Kota Padang.

Adapaun jenis dan sumber data yang terdapat dalam penelitian ini adalah Data primer dalam penelitian ini diperoleh melalui wawancara dan observasi yang berkaitan dengan pelaksanaan layanan e-Puskesmas di Puskesmas Ambacang Kecamatan Kurani Kota Padang. Data sekunder diperoleh melalui dokumen-dokumen seperti profil Puskesmas Ambacang Kota Padang (sejarah, visi dan misi, tugas pokok dan fungsi, struktur organisasi). Tekniik pengumpulan data yang digunakan adalah wawancara, observasi dan studi dokumentasi.

\section{HASIL DAN PEMBAHASAN}

\section{Pelaksanaan Layanan E-Puskesmas di Puskesmas Ambacang}

Berdasarkan hasil penelitian bahwa dengan adanya pelayanan berbasis elektronik, tujuan yang ingin dicapai oleh Puskesmas adalah meningkatkan pelayanan kesehatan dan derajat kesehatan yang setinggi-tingginya, yakni akan terciptanya masyarakat sehat yang mandiri sehingga terwujud pelayanan kesehatan yang lebih optimal lagi kepada masyarakat.

Melihat dari pelaksanaan layanan elektronik puskesmas di Puskesmas Ambacang diatas, ada beberapa teori dimensi elektronik government untuk mengukur peforma pemerintah dalam menerapkan e-Government diantaranya dilihat dari segi manfaat, efisiensi, partisipasi, transparansi, dan manajemen perubahan yang dikemukakan oleh Stifung (2001) dalam Indrajit (2005:46-48).

\section{Manfaat dari Elektronik Puskesmas}

Dalam pelaksanan layanan e-Puskesmas ini memang sangat bermanfaat bagi masyarakat yaitu dengan mudah mendaftar, berkonsultasi langsung dengan dokter, membaca artikel kesehatan, mengecek antrian dan nomor BPJS aktif atau tidaknya serta melihat informasi kesehatan di artikel yang telah disediakan. Petugas Puskesmas pun merasa sangat dimudahkan, dengan ini petugas merasa bahwa layanan e-Puskesmas mengurangi pelayanan yang lamban, sistem rujukan secara online ke rumah sakit bisa dilakukan dan data kesehatan masyarakat menjadi tepat sasaran dan Dinas Kesehatan semakin memudahkan untuk memantau kegiatan yang 
ada di Puskesmas, apakah puskesmas telah melaksanakan kewajibannya dengan sungguh-sungguh atau masih adanya kekurangan yang terjadi dalam pelayanan kesehatan.

Berdasarkan hasil penelitian, manfaat yang ada masih belum terlaksana dengan baik, terlihat pasien yang mendaftar masih mengantri untuk berobat bahkan tampak ada juga pasien yang berdiri saat pelayanan berobat di Puskesmas. Dengan diterapkannya teknologi informasi, masih sering terjadi keterlambatan pelayanan kesehatan di Puskesmas. Hal ini dikarenakan banyaknya pasien yang mendaftar. Meskipun e-Puskesmas sudah membuat pencarian data menjadi lebih cepat, namun proses pelayanan berobat yang harus dilakukan menggunakan jaringan internet dan terkadang jaringan tersebut tidak lancar menyebabkan pelayanan membutuhkan waktu yang lama jika pasien berjumlah banyak sehingga untuk pelayanan konvensional juga tetap dan setelah jaringannya bagus petugas memasukan lagi data kesehatan masyarakat ke aplikasi e-Puskesmas.

Dengan demikian pelaksanaan layanan ePuskesmas di Puskesmas Ambacang masih kurang dirasakan manfaatnya oleh pengguna, karena pada saat pelayanan masih adanya gangguan seperti jaringan yang lamban, kesalahan server yang terjadi dan pencatatan data pasien yang dilakukan petugas menjadi 2 (dua) kali. Dalam pelaksanaan pelayanan kesehatan di Puskesmas Ambacang pasien yang mendaftar masih mengantri lama untuk berobat dan belum memanfaatkan layanan ePuskesmas yang diterapkan oleh Puskesmas Ambacang Kota Padang.

\section{Efisiensi}

Pemanfaatan teknologi informasi dalam penyelenggaraan pelayanan kesehatan di Puskesmas Ambacang, diharapkan dapat mempercepat pelayanan kepada masyarakat dan mengurangi beban kerja Petugas Puskesmas Ambacang. Sistem aplikasi e-Puskesmas dinilai sudah memudahkan pekerjaan dari petugas pelayanan kesehatan Puskesmas Ambacang. Sistem aplikasi e-Puskesmas memudahkan petugas ketika pasien akan mendaftarkan diri untuk berobat di Puskesmas.

Hal tersebut dilakukan untuk lebih memudahkan dan mempercepat proses penyelesaian pelayanan kesehatan yang dilakukan oleh pasien, sehingga pasien tidak harus menunggu lama untuk dapat langsung di layani keluhan penyakitnya oleh dokter yang bertugas dan tidak harus untuk datang ke puskesmas hanya untuk mengantri di pendaftaran. Akan tetapi beberapa dari masyarakat (pasien) belum sepenuhnya menganggap layanan e-Puskesmas ini mudah dan cepat karena pelaksanaannya yang berbasis elektronik dan menggunakan jaringan internet.
Berdasarkan penelitian dilapangan, pelaksanaan layanan e-Puskesmas di Puskesmas Ambacang belum berjalan dengan efisien, karena masih menggunakan pelayanan yang manual, petugas Puskesmas belum maksimal dalam penggunaan teknologi informasi, pengetahuan masyarakat yang masih kurang untuk memanfaatkan pelayanan e-Puskesmas dan ketersediaan jaringan yang ada belum memenuhi kebutuhan dalam pelaksanaan layanan e-Puskesmas ini.

\section{Partisipasi}

Partisipatif, yakni pelayanan yang membuat masyarakat berperan dalam penyelenggaraan pelayanan publik dengan memperhatikan kebutuhan, harapan dan aspirasi masyarakat. Kaitannya dengan pelayanan berbasis teknologi informasi, maka partsipasi dilihat dari peran masyarakat dalam memanfaatkan teknologi informasi yang disediakan oleh Pemerintah kota Padang dalam pelayanan kesehatan di Puskesmas salah satunya di Puskesmas Ambacang.

Berdasarkan hasil penelitian yang penulis lakukan, dalam pelaksanaan layanan e-Puskesmas di Puskesmas Ambacang, keluhan yang dirasakan pasien adalah lambannya pelayanan yang diberikan karena jaringan maupun kesalahan server, Partisipasi yang dilakukan masyarakat masih terbilang kurang. Hal ini dapat dilihat dari masih kurangnya pengetahuan masyarakat dengan adanya pelayanan kesehatan e-Puskesmas dan Puskesmas ambacang kurang memberikan sosialisasi dan edukasi mengenai adanya layanan e-Puskesmas.

\section{Transparansi}

Transparansi, yaitu pelayanan kepada masyarakat yang bersifat terbuka, mudah dan bisa dimanfaatkan oleh semua pihak yang menginginkannya dan mudah dimengerti serta disediakan secara memadai. Terbuka disini berarti bahwa pelayanan kesehatan yang diselenggarakan melalui teknologi informasi yaitu sistem aplikasi e-Puskesmas dan media komunikasi dengan masyarakat seperti, SMS dan e mail harus bisa memberikan pelayanan yang transparan kepada masyarakat. Pelayanan yang terbuka adalah bahwa segala macam informasi mengenai kesehatan bisa didapat masyarakat melalui teknologi informasi dan media komunikasi yang disediakan untuk masyarakat.

Terkait dengan pelaksanan elektronik Puskesmas ini, sistemnya lebih terbuka atau transparan. Mulai dari masyarakat yang mendaftar melalui elektronik bisa mengecek jumlah antrian yang sedang berjalan di Puskesmas dan masyarakat yang sudah selesai berobat bisa melihat riwayat kesehatannya. Kenyataannya masyarakat yang mengecek antriannya di e-Puskesmas tidak sesuai dengan yang di lapangan dan riwayat 
kesehatan yang dapat dilihat oleh pasien tidak selalu masuk di aplikasi e-Puskesmas. Dinas Kesehatan dapat memantau pelaksanaan kegiatan pelayanan kesehatan di Puskesmas setiap harinya. Jadi tidak ada manipulasi terhadap data-data atau semua data kesehatan masyarakat harus masuk ke dalam e-Puskesmas.ini memperlihatkan bahwa petugas Puskesmas harus disiplin dalam bekerja karena masyarakat dan Dinas Kesehatan dapat melihatnya.

Berdasarkan hasil penelitian transparansi yang terjadi dalam pelayanan kesehatan di Puskesmas Ambacang belum berjalan dengan baik. Karena masih kurangnya informasi yang diterima oleh masyarakat dan masyarakat masih kurang mengetahui adanya pelayanan elektronik di Puskesmas Ambacang Kota Padang.

\section{Manajemen Perubahan}

Ini terkait dengan proses implementasi apakah ada proses review yang jelas dan dikelola dengan baik. Dilihat dari manajemen perubahan pelaksanaan layanan elektronik Puskesmas, dapat terlihat bahwa pemerintah telah melakukan inovasi dalam hal pelayanan kesehatan dengan mengeluarkan suatu program yang baru untuk dilaksanakan oleh pihak terkait guna memperbaiki sistem pelayanan yang diberikan terhadap masyarakat termasuk pasien yang ingin berobat selaku yang ingin mendapatkan pelayanan kesehatan di Puskesmas.

Dilihat dari karakteristik e-governmet bahwa e-gov merupakan suatu interaksi baru yang modern yang dilakukan antara pemerintah dengan masyarakat disini dapat dikatakan bahwa hal tersebut telah diterapkan oleh pemerintah dalam hal proses elektronik Puskesmas dengan melibatkan penggunaan teknologi informasi seperti sistem aplikasi e-Puskesmas yang dimiliki Puskesmas dan melakukan pelayanan kesehatan melalui elektronik dengan memanfaatkan jaringan internet serta pendaftaran untuk berobat dan pemantauan oleh Dinas Kesehatan yang dilakukan juga telah menggunakan sistem teknologi dengan menggunakan jaringan internet dan media elektronik. Hal tersebut dilakukan oleh pemerintah untuk memperbaiki mutu atau kualitas pelayanan agar lebih efektif dan efisien.

\section{Faktor-faktor Pendukung dan Penghambat dalam Penerapan e-Puskesmas di Puskesmas Ambacang Kota Padang}

Faktor pendukung pelaksanaan layanan ePuskesmas di Puskesmas Ambacang

1. Adanya perangkat hukum yang jelas dalam pelaksanaan pelayanan kesehatan yang berbasis elektronik ini di Puskesmas. Perangkat hukum tersebut yaitu dalam Permenkes tahun 2014 tentang Puskesmas, ada prinsip penyelenggaraan puskesmas itu ada enam salah satu indikatornya adalah melaksanakan atau menggunakan teknologi tepat guna yang bermanfaat untuk pelayanan kesehatan dan Surat Keputusan Kepala Puskesmas Ambacang Nomor 59//SK/KAPUS/I/2017 Tentang Pendaftaran e-Puskesmas.

2. Dana dan anggaran yang mencukupi dari segi pemeliharaan, perawatan dan pengadaan infrastruktur yang di butuhkan untuk menerapkan pelayanan berbasis elektronik di Puskesmas Ambacang Kota Padang ini.

3. Adanya perubahan paradigma pada pegawai Puskesmas yang lebih positif menjadikan seluruh pegawai dapat memahami pelaksanaannya dan membuat pegawai puskesmas disiplin dalam bekerja.

4. Adanya dukungan pimpinan terhadap penerapan ePuskesmas untuk penyelenggaraan pelayanan kesehatan di Puskesmas Ambacang dengan menggunakan teknologi informasi.

Faktor penghambat pelaksanaan layanan ePuskesmas di Puskesmas Ambacang

1. Sumber daya manusia yang bekerja di Puskesmas yang tidak semuanya dapat menguasai teknologi seperti komputer dan juga sistem yang tersedia, ditambah dengan keadaan SDM yang sudah kurang mengikuti perkembangan sehingga tidak bisa bekerja dengan sistem aplikasi e-Puskesmas dengan cepat dan tepat.

2. infrastruktur telekomunikasi yaitu computer untuk menginput data yang ada di Puskesmas Ambacang masih kurang memadai dan pengadaan komputer di Puskesmas Ambacang harus segera diadakan.

3. Konektivitas pada Puskesmas Ambacang masih kurang baik karena masih adanya kendala jaringan yang menghambat kegiatan pelayanan dengan menggunakan elektronik masih kurang optimal.

4. Kurangnya sosialisasi mengenai pelayanan kesehatan berbasis elektronik kepada masyarakat untuk mempermudah masyarakat ataupun penyelenggraan pelayanan itu sendiri.

5. Kurangnya kesadaran masyarakat mengenai adanya sistem aplikasi e-Puskesmas sehingga fungsi teknologi untuk menyediakan segala informasi kesehatan belum dimanfaatkan oleh masyarakat.

\section{PENUTUP}

\section{Simpulan}

Berdasarkan hasil penelitian dan pembahasan yang telah dikemukakan pada bab sebelumnya maka dapat disimpulkan beberapa hal seperti berikut ini :

Pelaksanaan layanan e-Puskesmas di Puskesmas Ambacang Kecamatan Kuranji Kota Padang belum 
terlaksana dengan baik sehingga pelaksanaan tersebut menjadi belum efektif. Dalam penerapan layanan ePuskesmas pada Puskesmas Ambacang Kota Padang terdapat beberapa faktor pendukung dan penghambat. Faktor pendukung yaitu, dana dan anggaran yang cukup memadai, adanya perangkat hukum yang jelas, perubahan paradigma pada pegawai di Puskesmas Ambacang serta adanya dukungan pimpinan terhadap penerapan ePuskesmas. Sedangkan untuk faktor penghambat yakni kurangnya ketersediaan infrastruktur yang memadai, tingkat konektivitas internet tidak sesuai dengan kebutuhan, sumber daya manusia yang masih terbatas dengan keahlian yang dimiliki, kurangnya sosialisasi yang dilakukan Puskesmas mengenai layanan e-Puskesmas serta kurangnya kesadaran masyarakat mengenai system aplikasi e-Puskesmas di Puskesmas Ambacang.

\section{Saran}

Berdasarkan hasil penelitian maka penulis mengemukakan beberapa saran sebagai berikut :

1. Sebaiknya pihak Puskesmas dapat mensosialisasikannya kepada masyarakat, terutama kepada mayasrakat yang berobat di Puskesmas karena pada umumnya pasien kurang ingin membaca dan sebaiknya Puskesmas memberikan edukasi mengenai pelayanan berbasis elektronik di Puskesmas. Sehingga pihak terkait tidak hanya mensosialisasikannya lewat baner karena belum tentu pasien bisa mengerti mengenai penggunaan layanan e-Puskesmas yang baru.

2. Sebaiknya pihak Dinas Kesehatan Kota Padang mengontrol secara kualitas server atau jaringan dan memperbaiki sistem yang bermasalah sehingga masyarakat selaku pengguna tidak terlalu lama menunggu dan pelayanan kesehatan di Puskesmas berjalan dengan baik.

3. Untuk masyarakat terutama yang berobat di Puskesmas diharapkan meningkatkan pemahaman dan kesadaran terhadap kemudahan layanan ePuskesmas serta ingin turut berpartisipasi. Jika masyarakat menyadari kemudahan yang di rasakan, keberadaan system aplikasi e-Puskesmas akan lebih efisien untuk dilakukan.

\section{DAFTAR PUSTAKA}

Indrajit, Richardus Eko. 2002. Electronic Government : Strategi Pembangunan dan Pengembangan Sistem Pelayanan Publik Berbasis Teknologi Digital. Jakarta :Andi Offset
Indrajit, Richardus Eko.2004, 2005. e-GOVERNMENT IN ACTION, Ragam Kasus Implementasi Suskses di Berbagai Belahan Dunia. Yogyakarta: Andi

Rahmad Buchari. 2016. Implementasi e-Service pada Organisasi Publik di Bidang pelayanan Publik di Kelurahan CibangkongKecamatan Batununggal. Jurnal Sosiohumaniora. Volume 18 No. 3 Nopember $2016: 227-232$

Tasmil.2014. Penilaian Tingkat Adopsi Aplikasi ePuskesmas dengan Perspektif Technology Acceptance Model. Jurnal Pekommas, Vol. 17 No. 3 Hal: 161-168

Santy Nurina Aprilia. 2014. Efektivitas Website Sebagai Media E-Government dalam Meningkatkan Pelayanan Elektronik Pemerintah Daerah (Studi Pada Website Pemerintah Daerah Kabupaten Jombang). Jurnal. Volume 17, No.

Nur Mas Ammah. 2015. Penerapan layanan e-health di Puskesmas Peneleh Kecamatan Genteng Kota Surabaya.

Ayu Aditya Oktavya. 2015. Penerapan e-Government pada pada Kantor Pelayanan Pajak Pratama dalam pemberian pelayanan di kota Bontang. Ejournal. Volume 3, No 3.

Peraturan Menteri Kesehatan Republik Indonesia Nomor 75 Tahun 2014 Tentang Pusat Kesehatan Masyarakat (Puskesmas)

Koran Padek Aplikasi_Layanan_Kesehatan_Diluncurkan.http:/ww w.newspadek. com. Diaksestanggal 23 januari 201 